\title{
Studies on the Group F Antigen of Lactobacilli: Antigenicity and Serological Specificity of Teichoic Acid Preparations
}

\author{
By K. W. KNOX AND MERILYN J. HEWETT \\ Institute of Dental Research, United Dental Hospital, Surry Hills, \\ N.S.W. 2oro, Australia \\ AND A. J. WICKEN \\ School of Microbiology, University of New South Wales, P.O. Box I, \\ Kensington, N.S.W. 2033, Australia
}

(Accepted for publication II November 1969)

\begin{abstract}
SUMMARY
The membrane glycerol teichoic acid of group F lactobacilli (e.g. Lactobacillus fermenti) has been identified as the group antigen. The most active preparations, obtained by phenol extraction, reacted readily with antisera and were antigenic when injected into rabbits with Freund's adjuvant. The products obtained by the action of trichloracetic acid were separable into a high molecular weight fraction, which reacted well with antiserum but was not a very effective antigen, and a low molecular weight fraction which was not antigenic and reacted weakly with group antisera. Specificity of the group antigen depends primarily on galactose with glucose being a minor contributor. However, the ability of galactose and glucose to inhibit the precipitin reaction differs considerably with different antisera. Teichoic acids from other strains of $L$. fermenti cross-reacted with the group antisera to varying extents but preparations from $L$. casei strains reacted only weakly.
\end{abstract}

\section{INTRODUCTION}

Most strains of lactobacilli can be divided into one of six groups, designated A to F, on the basis of the serological reaction of Lancefield acid extracts (Sharpe, I955; Sharpe \& Wheater, 1957). The specific antigens defining groups B and C are cellwall polysaccharides (Knox, I963), while teichoic acids have been identified as responsible for the specificities of groups A, D and E (Sharpe, Davison \& Baddiley, I964). Group F comprises strains of Lactobacillus fermenti and Sharpe et al. (I964) suggested that the specificity of this group might also depend on a teichoic acid. Teichoic acids occur as both wall and intracellular components and the tentative evidence for the group $\mathrm{F}$ antigen placed it in the latter category. It is generally considered that intracellular teichoic acid is associated with the cell membrane (Archibald, Baddiley \& Blumsom, I968), and the isolation from L. fermenti NCTC 699I of a teichoic acidphospholipid-glycolipid complex, referred to as lipoteichoic acid, is consistent with such a location (Wicken \& Knox, I970). The teichoic acid moiety of this complex has been shown to contain glucose and galactose substituents. Serological studies on lipoteichoic acid are described in this paper, and have led to the conclusion that it is the group antigen, with specificity primarily depending on galactose substituents. 
Further, the complex is antigenic, when injected with Freund's adjuvant into rabbits whereas lipid-free teichoic acid is not antigenic.

\section{METHODS}

Organisms. Strains were obtained originally from the National Collection of Type Cultures, Colindale, London (NCTC), the National Institute for Research in Dairying, Reading (NIRD), and from collections of salivary organisms at the Institute of Dental Research. These organisms were Lactobacillus fermenti NCTC 699I and laboratory strains 77 and I 26 representing serological group F (Knox \& Holmwood, I968), Lactobacillus casei NIRD H83I (group B) and L. casei NIRD R 094 and Lactobacillus helveticus (L. casei var. rhamnosus') NCTC 6375 (group C) (Knox, 1963).

Isolation of bacterial components. Teichoic acid was isolated from disrupted bacteria by the procedures previously described (Wicken \& Knox, 1970). Two fractions from disrupted Lactobacillus fermenti NCTC 699I were examined, namely the fraction sedimented at $100,000 \mathrm{~g}$ and the supernatant solution. Teichoic acid was extracted from a portion of each by either cold aqueous phenol, or cold trichloracetic acid (TCA), followed by further fractionation by column chromatography. Phenol-extracted material is designated P-teichoic acid; TCA yielded a high molecular weight fraction (HT-teichoic acid) and a low molecular weight fraction (LT-teichoic acid). Chemical studies on these products showed differences depending on the mode of extraction, though there were no significant differences between the products obtained by a particular procedure from the pellet of ribosomes and membrane fragments and from the supernatant solution (Wicken \& Knox, I970). Teichoic acids were isolated from L. fermenti strains 77 and 126 and $L$. case $i$ strains NIRD H 83 I, NIRD R 094 and NCTC 6375 by the phenol procedure. The cell wall of $L$. ferment $i$ was digested with a muralytic enzyme preparation from Streptomyces to yield a polysaccharide-peptidoglycan complex (fraction $\mathrm{S}_{3}$, Knox \& Holmwood, I968). This fraction will be referred to as cell-wall polysaccharide. Dr M. McCarty, Rockefeller University, New York, kindly provided a sample of polyglycerophosphate (glycerol teichoic acid) prepared from a group A streptococcal strain D 58 (type 3) (McCarty, 1959).

Preparation of antisera. All rabbits used for the production of antisera were 4- to 5-month-old male New Zealand Whites. Antisera to Lactobacillus fermenti NCTC 699 I were obtained by the intravenous injection of a suspension of bacteria into three rabbits (Sharpe, 1955). Rabbit 99 received two subsequent booster series of injections; antiserum collected after each series of injections is designated 99/1, 99/2 and 99/3 respectively. The antigenicity of teichoic acid preparations was examined by injecting an emulsion containing equal volumes of teichoic acid solution and Freund's adjuvant, complete or incomplete (Bacto Adjuvant $0638-60$ and 0639 respectively from Difco Laboratories, Detroit, Mich., U.S.A.). The emulsion contained I mg. teichoic acid/ $0.75 \mathrm{ml}$.; $0.25 \mathrm{ml}$. was injected subcutaneously into one site on the back and into two footpads; the injection procedure was repeated twice at 8-day intervals and the rabbits bled after a further 8 to Io days (cf. Burger, I966).

Quantitative precipitin reaction. Antiserum and antigen in $0.85 \%(\mathrm{w} / \mathrm{v}) \mathrm{NaCl}$ were mixed in a final volume of $0.6 \mathrm{ml}$. and incubated at $37^{\circ}$ for $\mathrm{I} \mathrm{hr}$ followed by 2 to 3 days at 2 to $4^{\circ}$. The precipitate was deposited by centrifugation and washed twice at 2 to $4^{\circ}$ with $0.85 \% \mathrm{NaCl}$. It was then dissolved in $0.6 \mathrm{ml}$. of $0 . \mathrm{I} \mathrm{N}-\mathrm{NaOH}$ and $0.4 \mathrm{ml}$. 
used in the estimation of protein with Folin-Ciocalteu's phenol reagent (Heidelberger \& MacPherson, 1943). By this procedure a sample of serum containing $120 \mu \mathrm{g}$. of antibody (using human IgG as the standard) gave an extinction at $750 \mathrm{~m} \mu$ in a $\mathrm{I} \mathrm{cm}$. cell of about 0.50 . Experiments were carried out in duplicate when determining precipitin curves, and in triplicate when inhibitions were being tested.

\section{RESULTS}

\section{Comparison of products from Lactobacillus fermenti NCTC 699I}

Reaction with antisera to whole L. fermenti. The antisera from three rabbits (designated 97, 98, 99) injected intravenously with strain NCTC 699I were examined for antibodies reacting with preparations of teichoic acid and cell-wall polysaccharide from this strain. HT- and P-teichoic acid preparations precipitated approximately equal amounts of antibody while LT-teichoic acid and cell-wall polysaccharide reacted only weakly (Fig. I.) No significant differences were observed in the reactivity of products isolated from the $100,000 \mathrm{~g}$ pellet and the supernatant solution. The results in Fig. I and for most of the reported experiments refer to preparations from the supernatant solution. From Fig. I. the amount of antibody precipitated from antiserum $99 / 3$ by P-teichoic acid corresponds to $6.3 \mathrm{mg}$. $/ \mathrm{ml}$. compared with $\mathrm{I} \cdot 4 \mathrm{mg} . / \mathrm{ml}$. when the cell-wall polysaccharide was added. For antisera $99 / \mathrm{I}$ and $99 / 2$ the corresponding values for Pteichoic acid were 3.5 and $4.5 \mathrm{mg}$. $/ \mathrm{ml}$.; for antisera 97 and 98 the values after one series of injections were 3.5 and $2.2 \mathrm{mg} . / \mathrm{ml}$. respectively.

Reaction with antisera to teichoic acid preparations. Antisera obtained by injection of products in Freund's adjuvant were examined for their reactivity with the different teichoic acid preparations (Fig. 2). A comparison of the reactivities of the teichoic acid

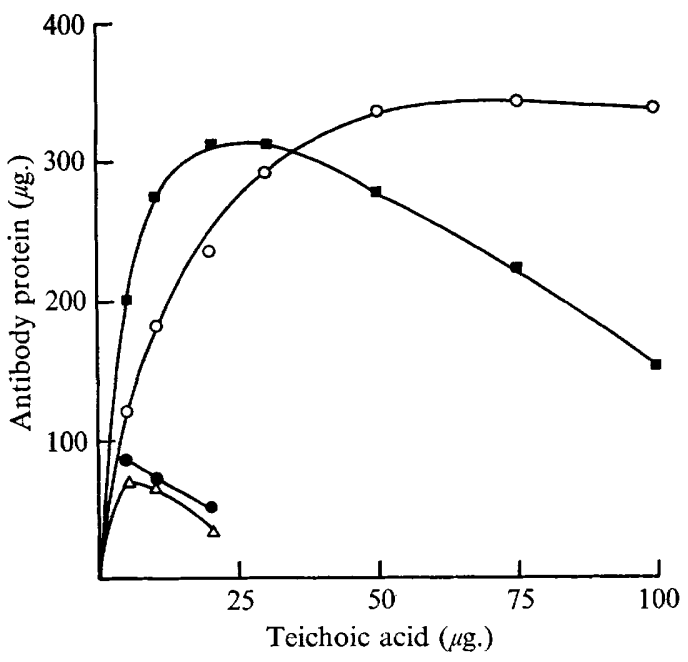

Fig. I

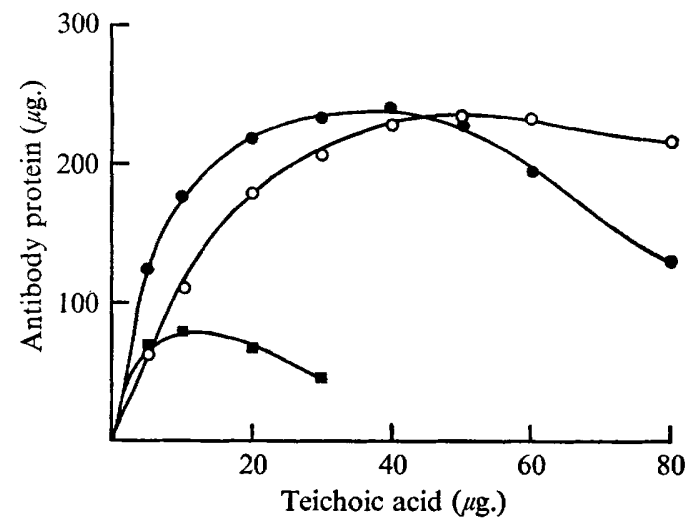

Fig. 2

Fig. I. Precipitation of teichoic acids and cell-wall polysaccharide by antiserum (50 $\mu 1$.) against $L$. fermenti (rabbit 99/3) $\square$, P-teichoic acid; O, HT-teichoic acid; ๑, LT-teichoic acid; $\triangle$, polysaccharide.

Fig. 2. Precipitation of teichoic acids by antiserum (O. I ml.) against P-teichoic acid (rabbit I48); P, P-teichoic acid; O, HT-teichoic acid; $\mathbf{D}$, LT-teichoic acid. 
preparations with those previously observed with serum 99/3 (Fig. I) indicated close similarities, but there was no cross-reaction with the cell-wall polysaccharide.

Similar results were obtained with other antisera against P-teichoic acid injected with complete and incomplete adjuvant, and with HT-teichoic acid in complete adjuvant, though antisera differed in the maximum amount of antibody precipitated. Table I summarizes the values for the antibody content of these antisera as determined by their reactivity with the injected fraction. Also included for comparison are the results for one series of intravenous injections of whole cells, and for disintegrated cells and LT-teichoic acid in complete adjuvant; in these cases the values were obtained with P-teichoic acid as the reactant in the precipitin test. The results indicate that Pteichoic acid was a more effective antigen than HT-teichoic acid, while LT-teichoic acid was not antigenic. It would also appear that alanine is not a major antigenic determinant as P-teichoic acid, which lacks alanine, was an effective antigen and also reacted with antiserum to HT-teichoic acid, which contains alanine (Wicken \& Knox, 1970).

Table I. Antibody content of antisera as determined by the quantitative precipitin method

\begin{tabular}{|c|c|c|}
\hline Preparation injected & Procedure* & Antibody (mg./ml.) \\
\hline Whole bacteria & Intravenous & $3 \cdot 5,2 \cdot 3,3 \cdot 5$ \\
\hline Disintegrated bacteria & Complete adjuvant & $\mathrm{I} \cdot 5, \mathrm{I} \cdot 6$ \\
\hline P-teichoic acid. & Incomplete adjuvant & $0 \cdot 7,1 \cdot 5$ \\
\hline & Complete adjuvant & $I \cdot 5,2 \cdot 4,5 \cdot 9$ \\
\hline HT-teichoic acid & Complete adjuvant & $0.8,0.8,0.6$ \\
\hline LT-teichoic acid & Complete adjuvant & $0 \cdot I, O \cdot I$ \\
\hline
\end{tabular}

* Details of injection procedures given in Methods.

Reactivity of HT-teichoic acid after degradation by alkali. Wicken \& Knox (1970) showed that a high molecular weight product of the action of TCA on P-teichoic acid contained a considerable amount of lipid while the corresponding low molecular weight fraction was lipid free. These results suggested that the differences in properties of HT- and LT-teichoic acid may relate to the lipid component of HT-teichoic acid. To remove fatty acids (and alanine) from HT-teichoic acid, a solution $(500 \mu \mathrm{g} .10 .5 \mathrm{ml}$.) was mixed with one volume of aqueous ammonia (sp.gr. 0.88) and left for $\mathrm{I} 6 \mathrm{hr}$ at room temperature. The solution was then evaporated to dryness in vacuo and reconstituted in $0.85 \% \mathrm{NaCl}$. The serological reactivity of the degraded material was compared with that for HT- and LT-teichoic acid, using antiserum to HT-teichoic acid in complete adjuvant. The results showed that ammonolysis yielded material with serological reactivity similar to that of LT-teichoic acid (Fig. 3). The removal of fatty acids by the ammonia treatment was confirmed by the procedures used previously (Wicken \& Knox, r970).

\section{Specificity of antisera}

Inhibition of the precipitin reaction by component sugars. The ability of D-alanine, D-glucose and D-galactose to inhibit the precipitin reaction was examined. The amounts of teichoic acid to be added were determined from quantitative precipitin curves and the volume of serum was such as to contain I00 to $\mathrm{I} 50 \mu \mathrm{g}$. antibody protein. D-Alanine (I00 $\mu$ moles) did not inhibit the precipitin reaction between HT-teichoic acid, which 
contains D-alanine, and homologous antisera, while the results with D-glucose and D-galactose (100 $\mu$ moles) depended on the serum used. The abilities of glucose and galactose to inhibit the precipitation of HT- and P-teichoic acid by antisera prepared against whole cells or P-teichoic acid also varied, depending on the serum used. Table 2 summarizes the values obtained with P-teichoic acid. Similar results were obtained for the inhibition of the precipitation of HT-teichoic acid; for example, the percentage inhibitions by glucose and galactose with antiserum I 32 were 9 and $31 \%$ respectively.

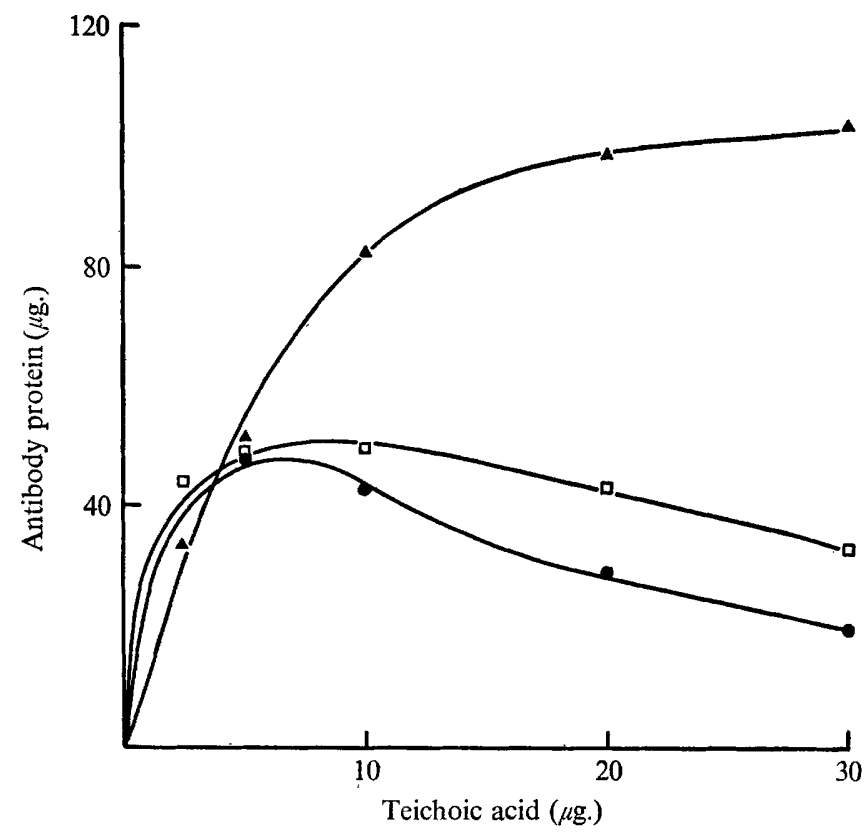

Fig. 3. Effect of alkali on serological reactivity of HT-teichoic acid with homologous antiserum (0.2 ml. from rabbit I36); $\Delta$, HT-teichoic acid; $\square$, alkali-degraded HT-teichoic acid; $\bullet$, LT-teichoic acid.

Table 2. Inhibition of precipitin reaction between $P$-teichoic acid and antisera

\begin{tabular}{lccc}
\multicolumn{4}{c}{$\begin{array}{c}\text { Inhibition }(\%) \\
\text { produced by sugar (100 } \mu \text { mole) }\end{array}$} \\
Preparation injected & Rabbit (no.) & Glucose & Galactose \\
Whole bacteria & 97 & I6 & 38 \\
& 98 & 10 & 32 \\
& $99 / 1^{*}$ & 8 & 5 \\
P-teichoic acid & $99 / 3^{*}$ & 0 & 5 \\
& 132 & 5 & 35 \\
& 146 & 6 & 10 \\
HT-teichoic acid & I47 & 7 & 36 \\
& I48 & 22 & 44 \\
& I36 & 8 & 47 \\
& I49 & 4 & I I \\
& I50 & 6 & I2
\end{tabular}

* Sera after the first and third series of injections respectively. 
More detailed studies of the inhibition by different amounts of glucose and galactose were carried out for some of the sera. Fig. 4 gives the results obtained with antiserum I 48 (50 $\mu \mathrm{l}$.) and P-teichoic acid (I0 $\mu \mathrm{g}$.). Fig. 5 compares the inhibitions by galactose of the reaction between antiserum $136(0.25 \mathrm{ml}$.) and each of the two preparations, P-teichoic acid (12.5 $\mu \mathrm{g})$ and HT-teichoic acid (25 $\mu \mathrm{g}$.).

Glucose and galactose are also the components of the cell-wall polysaccharide (Knox \& Holmwood, I968). D-Glucose and D-galactose (50 $\mu$ moles) inhibited the precipitin reaction between $10 \mu \mathrm{g}$. cell-wall polysaccharide and $0 . \mathrm{I} \mathrm{ml}$ serum $99 / 3$ by 62 and $10 \%$ respectively. In agreement with these results the major disaccharide obtained from the polysaccharide on mild acid hydrolysis has been shown (unpublished observations) to be indistinguishable in its properties from $3-O-\beta$-D-glucosyl-Dgalactose, previously identified as a component of a streptococcal polysaccharide (Montague \& Knox, 1968).

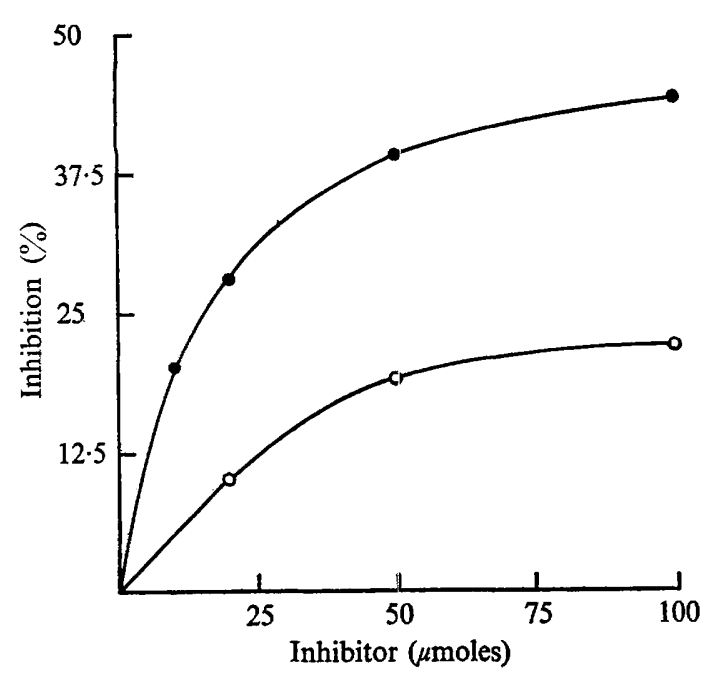

Fig. 4

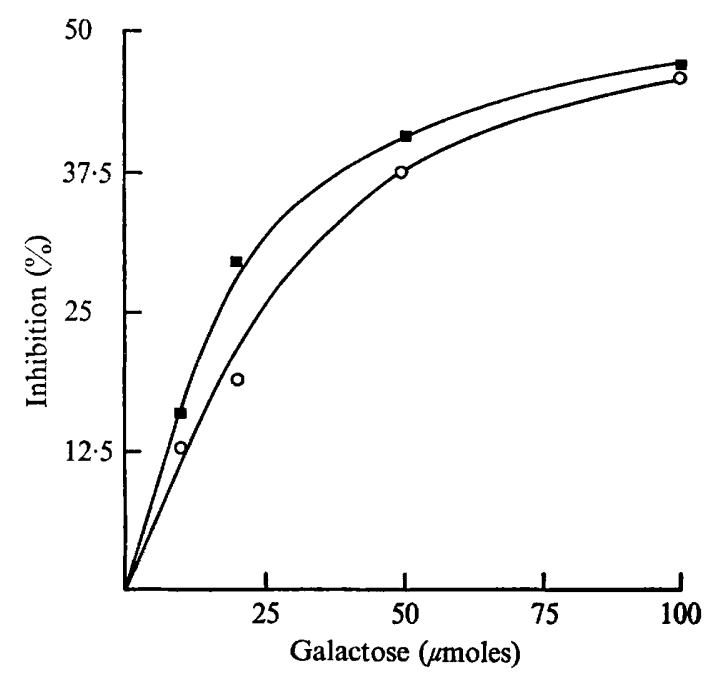

Fig. 5

Fig. 4. Inhibition of precipitin reaction between P-teichoic acid and homologous antiserum (rabbit I48) by D-glucose (O) and D-galactose ( $\bullet$ ).

Fig. 5. Inhibition of precipitation of P-teichoic acid $(\square)$ and HT-teichoic acid (O) by D- galactose.

Reactivity of antisera with teichoic acid preparations from other lactobacilli. P-teichoic acid preparations from Lactobacillus fermenti strains 77 and 126 and three strains of $L$. case $i$ were examined for their reaction with antisera obtained by injecting whole organisms (97, 99/3), P-teichoic acid (132, I46, I47, I48) and HT-teichoic acid (I49, I50). In each case the teichoic acid preparations were tested between 5 and $30 \mu \mathrm{g}$. to obtain maximum precipitation, and the amount of serum used contained 200 to $250 \mu \mathrm{g}$. of antibody precipitable by P-teichoic acid from $L$. fermenti NCTC 6991. In Table 3 , the maximum amount of antibody precipitated by each of the heterologous reactions is expressed as a percentage of that precipitated in the homologous reaction. The results are grouped in four categories depending on the antiserum: category I comprises the antisera to whole organisms while the remaining categories separate the antisera to teichoic acid according to the abilities of the component sugars to 
inhibit the precipitin reaction (see Table 2). When grouped in this manner, the degree of cross-reaction with antisera to teichoic acid is shown to be greatest with those antisera for which glucose and galactose are poor inhibitors (category II), and to be least for antiserum I 48 (category IV) where both glucose and galactose are good inhibitors; intermediate cross-reactions are given with antisera in category III, for which galactose alone is a good inhibitor. These distinctions are also evident with antisera to whole organisms (category I). Table 3 also includes for comparison the results of experiments described below on the extent of cross-reaction of streptococcal polyglycerophosphate with the antisera.

\section{Reactivity of antisera with streptococcal polyglycerophosphate}

Polyglycerophosphate at a concentration of I $\mathrm{mg}$. $/ \mathrm{ml}$. gave a strong reaction with antiserum $99 / 3$ by the qualitative ring precipitin test. However, when tested quantitatively by the procedure used above for lactobacilli, the cross-reaction corresponded to only $7 \%$ ( $320 \mu \mathrm{g}$. antibody precipitated by P-teichoic acid). Other antisera gave low results though values with antisera in category II of Table 3 were apparently the highest.

Polyglycerophosphate was purified from an acid extract of group A streptococci (McCarty, 1959), and its molecular size is probably comparable with that for LTteichoic acid rather than P-teichoic acid. LT-teichoic acid reacts weakly with antisera compared with P-teichoic acid (Fig I, 2) and therefore the reactions of polyglycerophosphate and LT-teichoic acid were compared; sufficient antiserum was used to precipitate 200 to $250 \mu \mathrm{g}$. antibody in the homologous reaction. The values obtained

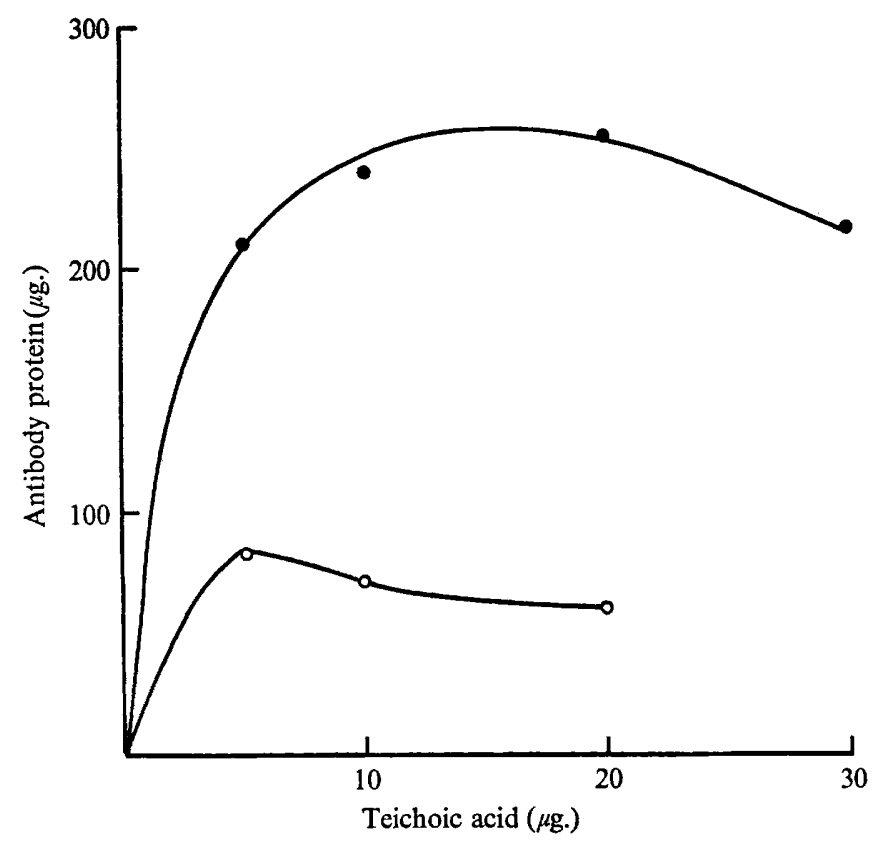

Fig. 6. Precipitation of LT-teichoic acid ( $\bullet)$ and streptococcal polyglycerophosphate $(O)$ by antiserum to P-teichoic acid (rabbit I46). 
for antiserum 146 are given in Fig. 6 and the results for all antisera are summarized in Table 3 .

When the results for the cross-reaction by polyglycerophosphate are compared with the other results in Table 3, they support the conclusion that the antisera differ in their specificity. Further support has been provided by preliminary experiments using sera absorbed with polyglycerophosphate for immuno-electrophoresis (unpublished method, with Miss R. Mollenhauer); absorption of antisera in category II (I46, I 50) almost completely removed the reaction with P-teichoic acid, whereas antisera in categories III and IV (I47, I48) retained most of their reactivity and there was no change in the immuno-electrophoretic pattern.

\title{
Table 3. Cross-reaction of antisera to Lactobacillus fermenti NCTC 699I with teichoic acid preparations from other organisms
}

\begin{abstract}
For strains of lactobacilli, values are expressed as a percentage of the amount of antibody precipitated by P-teichoic acid isolated from strain NCTC 699I; for polyglycerophosphate from a group A streptococcus, the values are expressed relative to LT-teichoic acid isolated from strain NCTC $699 \mathrm{r}$. The antisera have been grouped into four categories depending on the material injected and the specificity of the antisera (Table 2).
\end{abstract}

\begin{tabular}{|c|c|c|c|c|c|c|c|}
\hline \multirow[b]{3}{*}{ Category } & \multirow[b]{3}{*}{ Antiserum } & & \multicolumn{4}{|c|}{ Source of antigen } & \multirow{3}{*}{$\begin{array}{l}\text { Strepto- } \\
\text { coccus }\end{array}$} \\
\hline & & \multicolumn{2}{|c|}{ L. fermenti } & \multicolumn{3}{|c|}{ L. casei } & \\
\hline & & 77 & I 26 & н 831 & R 094 & 6375 & \\
\hline I & $\begin{array}{l}97 \\
99\end{array}$ & $\begin{array}{l}47 \\
47\end{array}$ & $\begin{array}{l}8 I \\
72\end{array}$ & $\begin{array}{l}\text { I5 } \\
22\end{array}$ & $\begin{array}{l}\text { I3 } \\
20\end{array}$ & $\begin{array}{l}\text { I } 6 \\
24\end{array}$ & $\begin{array}{r}<5 \\
24\end{array}$ \\
\hline II & $\begin{array}{l}146 \\
149 \\
150\end{array}$ & $\begin{array}{l}67 \\
58 \\
46\end{array}$ & $\begin{array}{l}74 \\
58 \\
60\end{array}$ & $\begin{array}{l}39 \\
52 \\
44\end{array}$ & $\begin{array}{l}26 \\
4 I \\
34\end{array}$ & $\begin{array}{l}28 \\
44 \\
39\end{array}$ & $\begin{array}{l}32 \\
32 \\
25\end{array}$ \\
\hline III & $\begin{array}{l}\text { I } 32 \\
147\end{array}$ & $\begin{array}{l}42 \\
38\end{array}$ & $\begin{array}{l}35 \\
38\end{array}$ & $\begin{array}{l}24 \\
22\end{array}$ & $\begin{array}{l}26 \\
22\end{array}$ & $\begin{array}{l}23 \\
24\end{array}$ & $\begin{array}{r}8 \\
15\end{array}$ \\
\hline IV & 148 & 29 & 33 & I6 & I5 & 17 & 20 \\
\hline
\end{tabular}

The suggestion that the group $\mathrm{F}$ antigen of lactobacilli is an intracellular glycerol teichoic acid (Sharpe et al. 1964) has been confirmed, while the isolation of the antigen as a lipid complex (P-or HT-teichoic acid) is consistent with its being a component of the protoplast mernbrane (Wicken \& Knox, 1970). The poor reaction of LT-teichoic acid with antisera probably relates to its low molecular weight, as Goodman \& Kabat (I960) have noted a similar relation between the amounts of antibody precipitated by dextrans of high and low molecular weights. Loss of reaction could also arise from loss of serological determinants, but this is less likely as LT-teichoic acid inhibited the agglutination of red blood cells sensitized with HT-teichoic acid (Hewett, Knox \& Wicken, 1970). The first suggestion is also supported by the observation that aqueous ammonia, which would disrupt the HT-teichoic acid complex by liberating fatty acids, yields a product with serological properties similar to those of LT-teichoic acid.

The antigenicity of teichoic acid preparations was determined by injecting products in Freund's complete adjuvant. If the results for P-teichoic acid are compared with those for disintegrated cells injected with adjuvant, it may be concluded that the antigen has been isolated without any significant decrease in activity. Previous studies on 
teichoic acids as group antigens showed that antisera could be obtained with whole cells or crude extracts but not with the products obtained by TCA extraction even if adjuvant were used (see Burger, I966). From the results with Lactobacillus fermenti these earlier observations could be explained by concluding that the lipoteichoic acid complex had been degraded by TCA to products which were too small to elicit antibody response in the rabbit. The injection procedure used for obtaining antibodies to lipoteichoic acid was similar to that employed by Burger (1966), who examined teichoic acids obtained from various organisms by a phenol extraction method. Burger (1966)

$(a)$

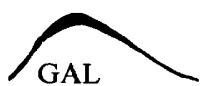

-GLY-P-GLY-P-GLY-P-GLY-P-GLY-P-GLY-P-GLY-P.

(b)

GAL

-GLY-P-GLY-P-GLY-P-GLY-P-GLY-P-GLY-P-GLY-P-
GAL

(c)

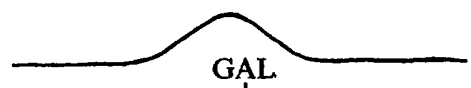

Fig. 7. Three types of antigenic determinants involving a galactose substituent on a sequence of glycerophosphate residues: (a) a small determinant group in which galactose is dominant; (b) a larger determinant group in which galactose plays a minor role and specificity is shown by glycerophosphate; $(c)$ similar to $(b)$ except that sequence of unsubstituted glycerophosphate residues is shorter. Gly $=$ glycerol, $\mathrm{P}=$ phosphate, $\mathrm{Gal}=$ galactose. The lines represent the affinity between the antibody combining sites and the determinant groups; the thicker the line the stronger the affinity for that portion of the determinant (cf. Lüderitz, Staub \& Westphal, 1966).

found that purified products did not elicit an antibody response whereas complexing with cationic precipitating agents to give particles of defined size rendered the preparation antigenic.

The specificity of teichoic acids generally depends on the substituent sugars (Staub, I 968), though when sugar is absent D-alanine can be the determinant (McCarty, 1964). Studies on the inhibition of the precipitation of teichoic acid from Lactobacillus fermenti indicate that in this case also the sugars rather than alanine are responsible for serological specificity. The abilities of D-glucose and D-galactose to inhibit the precipitin reaction vary considerably, with the values apparently depending on the rabbit injected rather than the source of antigen or the injection procedure. Thus galactose was an effective inhibitor ( 32 to $47 \%$ inhibition by $100 \mu$ moles) for six of the ten rabbits treated, while the results for glucose exceeded 10\% only twice.

Differences in specificity of antisera are also evident from a comparison of the degree of cross-reaction of antisera to Lactobacillus fermenti NCTC 699I with other strains of L. fermenti. The laboratory strains had been defined as group F by Knox \& Holmwood ( 1968 ) from the reaction of acid extracts with antiserum against strain NCTC $699 \mathrm{I}$ 
(Sharpe, 1955). It is now apparent from a quantitative comparison that the crossreaction is variable, and less than would be expected if the structures of the teichoic acid from each of the three strains were essentially the same. Information on the glycerol teichoic acids from strains 77 and 126 is limited to the observations (unpublished) that each contains glucose and galactose substituents. Serological differences have also been noted for the group D antigens from two strains of streptococci, and in this case differences in structure were detected (Wicken, Elliott \& Baddiley, 1963). It thus appears that when the group antigen is a membrane teichoic acid, the grouping of strains may depend on the relative degree of cross-reaction of strain-specific teichoic acids. In contrast, group-specific components of the wall, such as the polysaccharides of lactobacilli of groups B and C (Knox, 1963), are sufficiently similar in structure for there to be a strong cross-reaction between those of the same group.

As indicated by differences in sugar inhibitions (Table 2) and cross-reactions with other teichoic acids (Table 3), antisera to Lactobacillus fermenti NCTC 699I exhibit variable specificity. A diagrammatic representation of a model structure showing three types of reaction involving galactose as part of an antigenic determinant is provided in Fig. 7. This representation is analogous to that used in depicting the specific serological factors of Salmonella where a particular sequence of sugars has been shown to represent a number of antigenic determinants varying in size from two to four or more sugar residues (Lïderitz, Staub \& Westphal, I966). Figure $7 a$ depicts a specific grouping in which galactose is immunodominant, and may be regarded as representing the specificity of antisera in category III of Table 2, and part of the specificity of antiserum I 48 (category IV) and 97 (category I). Figure $7 b$ provides an example of a determinant grouping in which galactose would be a poor inhibitor and where a greater cross-reaction would occur with other teichoic acids containing unsubstituted sequences of glycerophosphate; this would account for the specificity of antisera in category II. Figure $7 c$ illustrates a specificity for which galactose is a minor component but the antisera might be expected to be more specific than for the structure shown in Fig. $7 b$ owing to the shorter sequence of unsubstituted glycerol units; antiserum 99 (category I) would be in this category. Such representations of antigenic determinants are therefore consistent with the observed properties of the antisera.

This work was supported by a grant (to K. W. K.) from the National Health and Medical Research Council of Australia.

\section{REFERENCES}

Archibald, A. R., Badd 30, 223.

Burger, M. M. (1966). Teichoic acids: Antigen determinants, chain separation and their location in the cell wall. Proceedings of the National Academy of Sciences of the United States of America 56,9 Io.

Goodman, J. W. \& Kaba.T, E. A. (I960). Immunochemical studies on crossreactions of antipneumococcal sera. III. The effect of variation in molecular weight on the cross-reactivity of dextran with type II antipneumococcal serum. Journal of Immunology 85, 392.

Heidelberger, M. \& MacPherson, C. F. C. (I943). Quantitative microestimation of antibodies in the sera of man and other animals. Science, New York 97, 405.

Hewett, M. J., KNox, K. W. \& Wicken, A. J. (I970). Studies on the group F antigen of lactobacilli: Detection of antibodies by haemagglutination. Journal of General Microbiology 6o, 315. 
KNox, K. W. (1963). Isolation of group-specific products from Lactobacillus casei and Lactobacillus casei var. rhamnosus. Journal of General Microbiology 31, 59.

KNox, K. W. \& Holmwood, K. J. (1968). Structure of the cell wall of lactobacilli. Role of muramic acid phosphate in Lactobacillus fermenti. Biochemical Journal 108, 363.

LÜDeritZ, O., Staub, A. M. \& Westrhal, O. (1966). Immunochemistry of $O$ and R antigens of Salmonella and related Enterobacteriaceae. Bacteriological Reviews 30, 193.

MCCARTY, M. (1959). The occurrence of polyglycerophosphate as an antigenic component of various Gram-positive bacterial species. Journal of Experimental Medicine rog, 36I.

MCCARTY, M. (1964). The role of D-alanine in the serological specificity of group A streptococcal glycerol teichoic acid. Proceedings of the National Academy of Sciences of the United States of America 52, 259.

Montague, E. A. \& Knox, K. W. (1968). Antigenic components of the cell wall of Streptococcus salivarius. Journal of General Microbiology 54, 237.

SHARPE, M. E. (1955). A serological classification of lactobacilli. Journal of General Microbiology r2, 107.

Sharpe, M. E., Davison, A. L. \& Baddiley, J. (1964). Teichoic acids and group antigens in lactobacilli. Journal of General Microbiology 34, 333.

ShARPE, M. E. \& WhEATER, D. M. (1957). Lactobacillus helveticus. Journal of General Microbiology I6, 676 .

Staub, A.-M. (1968). Bases chimiques de la spécificité des polyosides bactériens et des groupes sanguins. Bulletin de l'Institut Pasteur 66, I I 10.

Wicken, A. J., Elliotr, S. D. \& BadDiley, J. (I963). The identity of the streptococcal group D antigen with teichoic acid. Journal of General Microbiology 3I, 231.

WICKEN, A. J. \& KNOX, K. W. (1970). Studies on the group F antigen of lactobacilli: Isolation of a teichoic acid-lipid complex from Lactobacillus fermenti NCTC 6991. Journal of General Microbiology 6o, 293. 